Ambiente \& Água - An Interdisciplinary Journal of Applied Science
ISSN 1980-993X - doi:10.4136/1980-993X
www.ambi-agua.net
E-mail: ambi-agua@agro.unitau.br

\title{
Adubação com NPK e irrigação do girassol em Luvissolo: Comportamento vegetativo
}

\author{
doi: 10.4136/ambi-agua.1482
}

Received: 08 Aug. 2014; Accepted: 24 Sep. 2014

\section{Vinícius Batista Campos'; Lúcia Helena Garófalo Chaves²; Hugo Orlando Carvallo Guerra ${ }^{2 *}$}

\footnotetext{
${ }^{1}$ Instituto Federal de Educação, Ciência e Tecnologia do Amapá, Campus Laranjal do Jari, Amapá, Brasil

${ }^{2}$ Universidade Federal de Campina Grande (UFCG), Campina Grande, PB, Brasil Unidade Acadêmica de Engenharia Agrícola *Autor correspondente: e-mail: hugo_carvallo@hotmail.com, vinicius.campos@ifap.edu.br, lhgarofalo@hotmail.com
}

\section{RESUMO}

Entre as culturas utilizadas para a produção de biocombustíveis, o girassol é um das mais importantes. Apesar de existir informações na literatura, as necessidades hídricas e de nutrientes do girassol ainda não estão perfeitamente definidas. Com o objetivo de verificar os efeitos da adubação nitrogenada, fosfatada, potássica e o conteúdo de água disponível no solo (AD) sobre o comportamento vegetativo do girassol Embrapa 122 V2000, na Universidade Federal de Campina Grande, Campina Grande-PB, foi conduzido um experimento com quarenta e quatro tratamentos constituídos pela combinação de doses $\left(\mathrm{kg} \mathrm{ha}^{-1}\right)$ de $\mathrm{N}, \mathrm{P}$ e K de acordo com uma matriz baconiana, sendo 1: 0-0-0, 2: 0-80-80, 3: 80-80-80, 4: 100-80-80, 5: 60-0-80, 6: 60-100-80, 7: 60-120-80, 8: 60-80-0, 9: 60-80-80, 10: 60-80-100, 11: 60-80-120 e quatro conteúdos de água disponível (55, 70, 85 e 100\% da AD). O tratamento nove é o de referência, correspondendo às doses adotadas pelos produtores de girassol do Estado do Rio Grande do Norte. O delineamento foi inteiramente ao acaso em triplicata. Avaliou-se a altura de plantas, diâmetro do caule, número de folhas e área foliar, aos 40 e 60 dias após a semeadura. Os resultados indicaram que os efeitos da água disponível e adubação com NPK sobre a cultura do girassol ocorreram de forma independente, excetuando-se o número de folhas. Todas as variáveis apresentaram comportamento linear crescente em função da água disponível do solo, exceto a área foliar. Para as condições estudadas, as doses 100, 80 e $80 \mathrm{~kg} \mathrm{ha}^{-1}$ de $\mathrm{N}, \mathrm{P}_{2} \mathrm{O}_{5}$ e $\mathrm{K}_{2} \mathrm{O}$, respectivamente, proporcionaram os maiores índices de crescimento.

Palavras-chave: água disponível, Helianthus annuus L., nutrição mineral.

\section{NPK fertilization and irrigation of sunflowers in Luvisol: Vegetative behavior}

\section{ABSTRACT}

The sunflower is one of the most important crops used for the production of biofuels. While the literature does contain some information, the hydric and nutritional requirements of sunflowers are still not completely defined. In order to correct this deficiency, an experiment 
was conducted at the Federal University of Campina Grande, Campina Grande, Paraíba State, Brazil, with the aim of evaluating the effect of nitrogen, phosphate, and potassium fertilization and available soil water (AW) on the behavior of Sunflower cv. Embrapa 122 V2000. The experiment consisted of 44 treatments with compound fertilizers using a Baconian Matrix (1: 0-0-0, 2: 0-80-80, 3: 80-80-80, 4: 100-80-80, 5: 60-0-80, 6: 60-100-80, 7: 60-120-80, 8: 60-80-0, 9: 60-80-80, 10:60-80-100, 11:60-80-120 kg ha-1 of N, P and K, respectively, and four difference quantities of available soil water $(55,70,85$ and 100\%). The $9^{\text {th }}$ compound fertilizer treatment was considered the reference since its doses are those used by the region's sunflower growers in Rio Grande do Norte State. The treatments were arranged in a completely randomized design with three replications. The height, stem diameter, number of leaves and leaf area of the plants were evaluated at 40 and 60 days after sowing. The results showed that the effects of available soil water and NPK fertilization on sunflower crop occurred independently for all variables except for the number of leaves. All variables increased linearly as a function of available soil water, except for leaf area. For the conditions studied, the doses 100,80 and $80 \mathrm{~kg} \mathrm{ha}^{-1}$ of $\mathrm{N}, \mathrm{P}_{2} \mathrm{O}_{5}$ and $\mathrm{K}_{2} \mathrm{O}$ resulted in the highest growth rates, respectively.

Keywords: available soil water, Helianthus annuus L., mineral nutrition.

\section{INTRODUÇÃO}

O girassol (Helianthus annuus L.) é uma dicotiledônea anual da família Asteraceae, originária da América do Norte, mundialmente cultivada em todos os continentes, tendo como principais produtores a Rússia, Ucrânia, Argentina, entre outros (FAO, 2008). Essa planta se adapta bem a diversas condições edafoclimáticas, caracterizando-se pela tolerância a baixas temperaturas na fase inicial de desenvolvimento e pela relativa resistência a déficits hídricos. Pode ser cultivada em todas as regiões do país, pois o rendimento é pouco influenciado pelas latitudes e altitudes, assim como pelo fotoperíodo, o que facilita a expansão do cultivo no Brasil (Zobiole et al., 2010). É uma espécie extremamente versátil, tendo como principais produtos o óleo, produzido de seus aquênios (frutos), ração animal, além de ser utilizada na alimentação humana e como planta ornamental.

O girassol é uma planta que absorve uma quantidade muito grande dos principais macronutrientes, em comparação com a soja, milho e o trigo. Para que possa expressar todo o seu potencial produtivo, o suprimento de água e nutrientes deve ser adequado desde o início do seu desenvolvimento, principalmente a partir da emissão do botão floral, quando inicia o período de maior crescimento, acompanhado do aumento no consumo de água e da demanda nutricional.

De modo geral, as quantidades de nitrogênio, fósforo e de potássio recomendadas para o cultivo do girassol, variam de 40 a $60 \mathrm{~kg} \mathrm{ha}^{-1}$ de $\mathrm{N}, 40$ a $80 \mathrm{~kg} \mathrm{ha}^{-1} \mathrm{de}_{2} \mathrm{P}_{2} \mathrm{O}_{5}$ e 40 a $80 \mathrm{~kg} \mathrm{ha}^{-1}$ de $\mathrm{K}_{2} \mathrm{O}$. Entretanto, na literatura são encontradas recomendações com diferentes combinações destes elementos, em decorrência das condições edafoclimáticas e tipo de variedade que está sendo cultivada. Castro e Oliveira (2005), por exemplo, recomendam a adubação do girassol utilizando doses entre 40 a $60 \mathrm{~kg} \mathrm{ha}^{-1}$ de $\mathrm{N}$, devendo se utilizar em solos com médio teor de fósforo e potássio, 18 e $33 \mathrm{~kg} \mathrm{ha}^{-1}$, respectivamente. Quaggio e Ungaro (1997) indicam para o Estado de São Paulo, a aplicação de $50 \mathrm{~kg} \mathrm{ha}^{-1}$ de N, 20 a $70 \mathrm{~kg} \mathrm{ha}^{-1}$ de $\mathrm{P}_{2} \mathrm{O}_{5}$ e 20 a $60 \mathrm{~kg} \mathrm{ha}$ de $\mathrm{K}_{2} \mathrm{O}$.

A planta do girassol tem baixa eficiência no uso da água, uma vez que, cada litro de água consumido produz menos de dois gramas de matéria seca. Uma adequada disponibilidade de água durante o período da germinação à emergência é necessária para a obtenção de uma boa uniformidade na população de plantas. As fases do desenvolvimento da planta mais sensíveis ao déficit hídrico são do início da formação do capítulo ao começo da floração (afeta mais o 
rendimento de grãos) e da formação e enchimento de grãos, que é a fase de maior consumo de água pelo girassol (afeta mais a produção de óleo). De uma forma bastante prática, a fase mais crítica ao déficit hídrico é o período compreendido entre cerca de 10 a 15 dias antes do início do florescimento e 10 a 15 dias após o final da floração (Embrapa, 2000). Apesar dessas informações, e de outras disponibilizadas na literatura, as necessidades hídricas do girassol ainda não estão perfeitamente definidas, podendo variar de 200 a $900 \mathrm{~mm}$ ciclo $^{-1}$, o que constituiu o incentivo para novas pesquisas nesta área.

Neste sentido, objetivou-se avaliar o efeito da adubação mineral com NPK sobre o comportamento vegetativo do girassol variedade Embrapa 122 V2000, para diferentes níveis de água disponível no solo.

\section{MATERIAL E MÉTODOS}

\section{1. Área de estudo}

O experimento foi realizado em estufa agrícola, no período entre julho e outubro de 2010 na Unidade de Engenharia Agrícola do Centro de Tecnologia e Recursos Naturais da Universidade Federal de Campina Grande (UFCG) localizada no município de Campina Grande, PB, cujas coordenadas geográficas são: 654'10" S e 3550’02”O.

Segundo a classificação de Köppen, o clima da região é Csa (mesotérmico subúmido), temperatura média anual oscilando entre 19,2 e $27,5^{\circ} \mathrm{C}$ e umidade relativa do ar média de $83 \%$.

\subsection{Tratamentos e delineamento experimental}

O delineamento experimental foi inteiramente ao acaso, com três repetições, sendo testados 44 tratamentos de uma matriz baconiana formada por quatro níveis de água disponível no solo $(55,70,85$ e $100 \%)$, submetidos a quatro doses de nitrogênio $(0,60$, 80 e $100 \mathrm{~kg} \mathrm{ha}^{-1}$ de $\left.\mathrm{N}\right)$; fósforo $\left(0,80,100\right.$ e $120 \mathrm{~kg} \mathrm{ha}^{-1}$ de $\left.\mathrm{P}_{2} \mathrm{O}_{5}\right)$ e potássio $(0,80,100$ e $120 \mathrm{~kg} \mathrm{ha}^{-1} \mathrm{de}_{2} \mathrm{O}$ ), totalizando 132 parcelas (Tabela 1). A dose de adubação referencial foi $60,80,80 \mathrm{~kg} \mathrm{ha}^{-1}$ de $\mathrm{N}, \mathrm{P}$ e K, respectivamente.

\subsection{Condução do experimento}

O solo utilizado no experimento foi proveniente de um Luvissolo Crômico órtico coletado na camada superficial $(0-20 \mathrm{~cm})$, no município de Boqueirão, PB, o qual foi seco ao ar, destorroado, homogenizado, peneirado e caracterizado quanto os aspectos físicos e químicos, segundo metodologia descrita pela Embrapa (1997), tendo como características: $\mathrm{pH}$ $\left(\mathrm{H}_{2} \mathrm{O}\right)=5,7 ; \mathrm{Ca}^{2+}=3,40 \mathrm{cmol}_{\mathrm{c}} \mathrm{dm}^{-3} ; \mathrm{Mg}^{2+}=1,85 \mathrm{cmol}_{\mathrm{c}} \mathrm{dm}^{-3} ; \mathrm{Na}^{+}=0,18 \mathrm{cmol}_{\mathrm{c}} \mathrm{dm}^{-3}$; $\mathrm{K}^{+}=0,16 \mathrm{cmol}_{\mathrm{c}} \mathrm{dm}^{-3} ; \mathrm{H}^{+}+\mathrm{Al}^{3+}=2,15 \mathrm{cmol}_{\mathrm{c}} \mathrm{dm}^{-3}$; matéria orgânica $=6,03 \mathrm{~g} \mathrm{dm}^{-3} ; \mathrm{P}=14,63$ $\mathrm{mg} \mathrm{dm}$; areia $=644 \mathrm{~g} \mathrm{~kg}^{-1}$; silte $=137 \mathrm{~g} \mathrm{~kg}^{-1}$; argila $=219 \mathrm{~g} \mathrm{~kg}^{-1}$; densidade do solo $=1,31 \mathrm{~kg} \mathrm{dm}^{-3}$; densidade de partículas $=2,68 \mathrm{~kg} \mathrm{dm}^{-3}$ e porosidade total $=51 \%$.

Cada unidade experimental foi constituída por um vaso plástico com capacidade volumétrica de $35 \mathrm{~L}$ onde foram acondicionados $32 \mathrm{~kg}$ de solo. Um tubo de acesso de PVC para medição do conteúdo de água do solo com uma sonda segmentada FDR (Reflectometria no Domínio da Frequência) DIVINNER - 2000 foi inserido no solo dos tratamentos a ser mantidos a $100 \%$ da água disponível no solo para as plantas. O volume de água para $100 \%$ da água disponível no solo (AD) foi calculado determinando o conteúdo de água do solo na capacidade de campo (CC) e no ponto de murcha permanente (PMP) no laboratório $(\mathrm{AD}=\mathrm{CC}-\mathrm{PMP})$. Os volumes de reposição de água para os demais tratamentos foram calculados proporcionalmente a partir do volume de água para $100 \%$ da água disponível no solo. As irrigações foram conduzidas diariamente visando manter os respectivos níveis de água dos tratamentos. 
A adubação com $\mathrm{N}, \mathrm{P}_{2} \mathrm{O}_{5}$ e $\mathrm{K}_{2} \mathrm{O}$ foram realizadas na forma de uréia, superfosfato triplo e cloreto de potássio, respectivamente. Independente do tratamento utilizado, o fósforo foi aplicado integralmente na fundação e o potássio parcelado em três aplicações com mesmo quantitativo, em fundação, aos 28 e 52 dias após a semeadura (DAS). O nitrogênio também foi parcelado, sendo $50 \%$ da dose aos 28 DAS e os demais aos 52 DAS. Foi fornecido também a cada unidade experimental, aos 28 DAS, o correspondente a $2 \mathrm{~kg} \mathrm{ha}^{-1}$ de boro, proveniente de ácido bórico.

O semeio foi realizado no dia 16 de julho de 2010, sendo diretamente no vaso, utilizando 10 sementes de girassol, variedade Embrapa 122 V-2000, distribuídas e distanciadas de forma equidistante, a uma profundidade de $0,02 \mathrm{~m}$. Aos $20 \mathrm{DAS}$, realizou-se o desbaste, deixando apenas uma planta por unidade experimental.

Tabela 1. Doses de nitrogênio $(\mathrm{N})$, fósforo $(\mathrm{P})$ e potássio $(\mathrm{K})$ correspondentes aos tratamentos que compuseram a matriz baconiana.

\begin{tabular}{|c|c|c|c|c|c|c|c|c|c|}
\hline \multirow{2}{*}{ Tratamentos } & $\mathbf{N}$ & $\mathbf{P}_{2} \mathbf{O}_{5}$ & $\mathbf{K}_{2} \mathbf{O}$ & \multirow{2}{*}{$\frac{\text { Água }}{\%}$} & \multirow{2}{*}{ Tratamentos } & $\mathbf{N}$ & $\mathbf{P}_{2} \mathbf{O}_{5}$ & $\mathrm{~K}_{2} \mathrm{O}$ & \multirow{2}{*}{$\frac{\text { Água }}{\%}$} \\
\hline & \multicolumn{3}{|c|}{----- kg ha ${ }^{-1}$} & & & \multicolumn{3}{|c|}{----- kg ha"----- } & \\
\hline 1 & 0 & 0 & 0 & 55 & 23 & 0 & 0 & 0 & 85 \\
\hline 2 & 0 & 80 & 80 & 55 & 24 & 0 & 80 & 80 & 85 \\
\hline 3 & 80 & 80 & 80 & 55 & 25 & 80 & 80 & 80 & 85 \\
\hline 4 & 100 & 80 & 80 & 55 & 26 & 100 & 80 & 80 & 85 \\
\hline 5 & 60 & 0 & 80 & 55 & 27 & 60 & 0 & 80 & 85 \\
\hline 6 & 60 & 100 & 80 & 55 & 28 & 60 & 100 & 80 & 85 \\
\hline 7 & 60 & 120 & 80 & 55 & 29 & 60 & 120 & 80 & 85 \\
\hline 8 & 60 & 80 & 0 & 55 & 30 & 60 & 80 & 0 & 85 \\
\hline $9^{*}$ & 60 & 80 & 80 & 55 & $31^{*}$ & 60 & 80 & 80 & 85 \\
\hline 10 & 60 & 80 & 100 & 55 & 32 & 60 & 80 & 100 & 85 \\
\hline 11 & 60 & 80 & 120 & 55 & 33 & 60 & 80 & 120 & 85 \\
\hline 12 & 0 & 0 & 0 & 70 & 34 & 0 & 0 & 0 & 100 \\
\hline 13 & 0 & 80 & 80 & 70 & 35 & 0 & 80 & 80 & 100 \\
\hline 14 & 80 & 80 & 80 & 70 & 36 & 80 & 80 & 80 & 100 \\
\hline 15 & 100 & 80 & 80 & 70 & 37 & 100 & 80 & 80 & 100 \\
\hline 16 & 60 & 0 & 80 & 70 & 38 & 60 & 0 & 80 & 100 \\
\hline 17 & 60 & 100 & 80 & 70 & 39 & 60 & 100 & 80 & 100 \\
\hline 18 & 60 & 120 & 80 & 70 & 40 & 60 & 120 & 80 & 100 \\
\hline 19 & 60 & 80 & 0 & 70 & 41 & 60 & 80 & 0 & 100 \\
\hline $20^{*}$ & 60 & 80 & 80 & 70 & $42^{*}$ & 60 & 80 & 80 & 100 \\
\hline 21 & 60 & 80 & 100 & 70 & 43 & 60 & 80 & 100 & 100 \\
\hline 22 & 60 & 80 & 120 & 70 & 44 & 60 & 80 & 120 & 100 \\
\hline
\end{tabular}

*Tratamentos de referência, que corresponde às doses de adubação usadas para girassol no Estado do Rio Grande do Norte.

\subsection{Variáveis avaliadas e análise estatística}

Aos 40 e 60 dias após a semeadura (DAS) avaliou-se a altura de plantas (AP), diâmetro caulinar (DC), número de folhas (NF) e área foliar (AF). Na contagem das folhas foram consideradas as que apresentaram comprimento mínimo de $0,03 \mathrm{~m}$ e que estivessem sadias, 
ou seja, fotossinteticamente ativas; a medição do diâmetro do caule foi feito com o auxílio de um paquímetro, com as leituras sendo efetuadas na região do colo de cada planta a $0,05 \mathrm{~m}$ do solo; o comprimento do caule foi definido mensurando-se a distância entre o colo da planta e a inserção da folha mais nova no período da colheita das plantas; o cálculo da área foliar foi feita segundo metodologia proposta por Maldaner et al. (2009) cuja fórmula é:

$$
\mathrm{AF}=0,1328 \times \mathrm{C}^{2,5569}
$$

em que:

$\mathrm{C}=$ comprimento da nervura central de cada folha da planta sendo que o somatório final das áreas por folha fornecia o valor da área foliar da planta.

Os dados obtidos foram submetidos à análise de variância e de regressão, utilizando o software estatístico SAEG (Eyclydes, 1997).

\section{RESULTADOS E DISCUSSÃO}

A altura de plantas foi afetada significativamente pela adubação NPK e pela irrigação conforme a Tabela 2.

Tabela 2. Resumo das análises de variância para altura de plantas (AP) e diâmetro caulinar (DC) do girassol (variedade Embrapa 122-V2000) aos 40 e 60 dias após a semeadura (DAS) submetido à adubação com NPK e conteúdo de água disponível no solo.

\begin{tabular}{|c|c|c|c|c|c|}
\hline \multirow{3}{*}{ Fonte de variação } & \multirow{3}{*}{ GL } & \multicolumn{4}{|c|}{ Quadrado médio } \\
\hline & & \multicolumn{2}{|c|}{ Altura de plantas (cm) } & \multicolumn{2}{|c|}{ Diâmetro de caule (mm) } \\
\hline & & 40 DAS & 60 DAS & 40 DAS & 60 DAS \\
\hline Adubação (NPK) & 10 & $1217,566^{* *}$ & $284,644^{* *}$ & $6,373^{* *}$ & $1,621^{\mathrm{ns}}$ \\
\hline Irrigação (I) & 3 & $1074,617^{* *}$ & $4099,089^{* *}$ & $39,011^{* *}$ & $64,726^{* *}$ \\
\hline NPK x I & 30 & $131,25937^{\mathrm{ns}}$ & $73,729^{\text {ns }}$ & $2,009^{\mathrm{ns}}$ & $0,927^{\mathrm{ns}}$ \\
\hline Resíduo & 88 & 119,186 & 109,101 & 1.510 & 0,956 \\
\hline Total & 131 & - & - & - & - \\
\hline CV (\%) & - & 11,17 & 10,46 & 11,48 & 8,57 \\
\hline $\mathrm{N}$ - Regressão Linear & 1 & $80,504^{\text {ns }}$ & $123,697^{\text {ns }}$ & $0,165^{\mathrm{ns}}$ & $3,978^{*}$ \\
\hline N - Regressão Quadrática & 1 & $52,083^{\text {ns }}$ & $11,701^{\mathrm{ns}}$ & $2,851^{\mathrm{ns}}$ & $0,500^{\mathrm{ns}}$ \\
\hline P - Regressão Linear & 1 & $874,666^{\text {ns }}$ & $96,013^{\text {ns }}$ & $35,113^{* *}$ & $0,793^{\text {ns }}$ \\
\hline P - Regressão Quadrática & 1 & $3687,152^{* *}$ & $280,333^{\text {ns }}$ & $0,653^{\text {ns }}$ & $0,020^{\mathrm{ns}}$ \\
\hline K - Regressão Linear & 1 & $33,376^{\mathrm{ns}}$ & $960,800^{* *}$ & $0,0006^{\mathrm{ns}}$ & $0,126^{\mathrm{ns}}$ \\
\hline K - Regressão Quadrática & 1 & $453,255^{\mathrm{ns}}$ & $141,453^{\text {ns }}$ & $0,140^{\mathrm{ns}}$ & $0,725^{\mathrm{ns}}$ \\
\hline I - Regressão Linear & 1 & $2999,041^{* *}$ & $12188,784^{* *}$ & $112,592^{* *}$ & $189,765^{* *}$ \\
\hline I - Regressão Quadrática & 1 & $158,183^{\text {ns }}$ & $14,467^{\mathrm{ns}}$ & $1,401^{\mathrm{ns}}$ & $0,967^{\mathrm{ns}}$ \\
\hline N - Linear x I Linear & 1 & $0,300^{\mathrm{ns}}$ & $4,189^{\mathrm{ns}}$ & $2,493^{\mathrm{ns}}$ & $0,015^{\mathrm{ns}}$ \\
\hline P - Linear x I Linear & 1 & $7,824^{\mathrm{ns}}$ & $109,203^{\text {ns }}$ & $3,101^{\mathrm{ns}}$ & $1,333^{\mathrm{ns}}$ \\
\hline K - Linear x I Linear & 1 & $91,576^{\mathrm{ns}}$ & $190,403^{\text {ns }}$ & $0,141^{\mathrm{ns}}$ & $0,027^{\mathrm{ns}}$ \\
\hline
\end{tabular}

Nota: *, ${ }^{* *}$ significativo a 5 e $1 \%$, respectivamente, e ${ }^{\text {ns }}$ não significativo, pelo teste F. GL: Grau de liberdade. CV: coeficiente de variação. 
Os valores da altura da planta submetida às doses de $\mathrm{P}_{2} \mathrm{O}_{5}$ ajustaram, aos 40 DAS, ao modelo de regressão polinomial de segunda ordem (quadrática). Já, com as doses de $\mathrm{K}_{2} \mathrm{O}$, aos 60 DAS, os valores da altura de plantas ajustaram de forma linear, corroborando Ahmad (1989) que indica que a altura de plantas é significativamente afetada pela aplicação de $\mathrm{K}_{2} \mathrm{O}$ (Figura $1 \mathrm{~A}$ e B). Isto porque o potássio ocasiona $\mathrm{o}$ funcionamento dos estômatos, assimilando $\mathrm{CO}_{2}$ e aumentando a taxa fotossintética, influenciando, consequentemente, o crescimento das plantas. Os níveis de água utilizada para as plantas, tanto aos 40 como aos 60 DAS, influenciaram linearmente a altura das plantas (Figura 1C). Observou-se que as maiores alturas das plantas de girassol foram obtidas com as maiores doses de fósforo e potássio $\left(120 \mathrm{~kg} \mathrm{ha}{ }^{-1}\right)$. Segundo Taiz e Zeiger (2004), o fósforo é componente de muito fósforo-açúcares necessário na fotossíntese, respiração e participa na formação de nucleotídeos (DNA e RNA) e de fosfolipídios presentes nas membranas, por isso, é importante no metabolismo vegetal influenciando o crescimento das plantas.

$\mathrm{O}$ manejo da água disponível elevou linearmente a altura das plantas de girassol variedade Embrapa 122 V2000. Analisando as equações de regressão (Figura 1C), observou-se um acréscimo de 22,29 e $29,67 \%$ entre os tratamentos extremos de reposição de água aos 40 e 60 DAS, respectivamente.
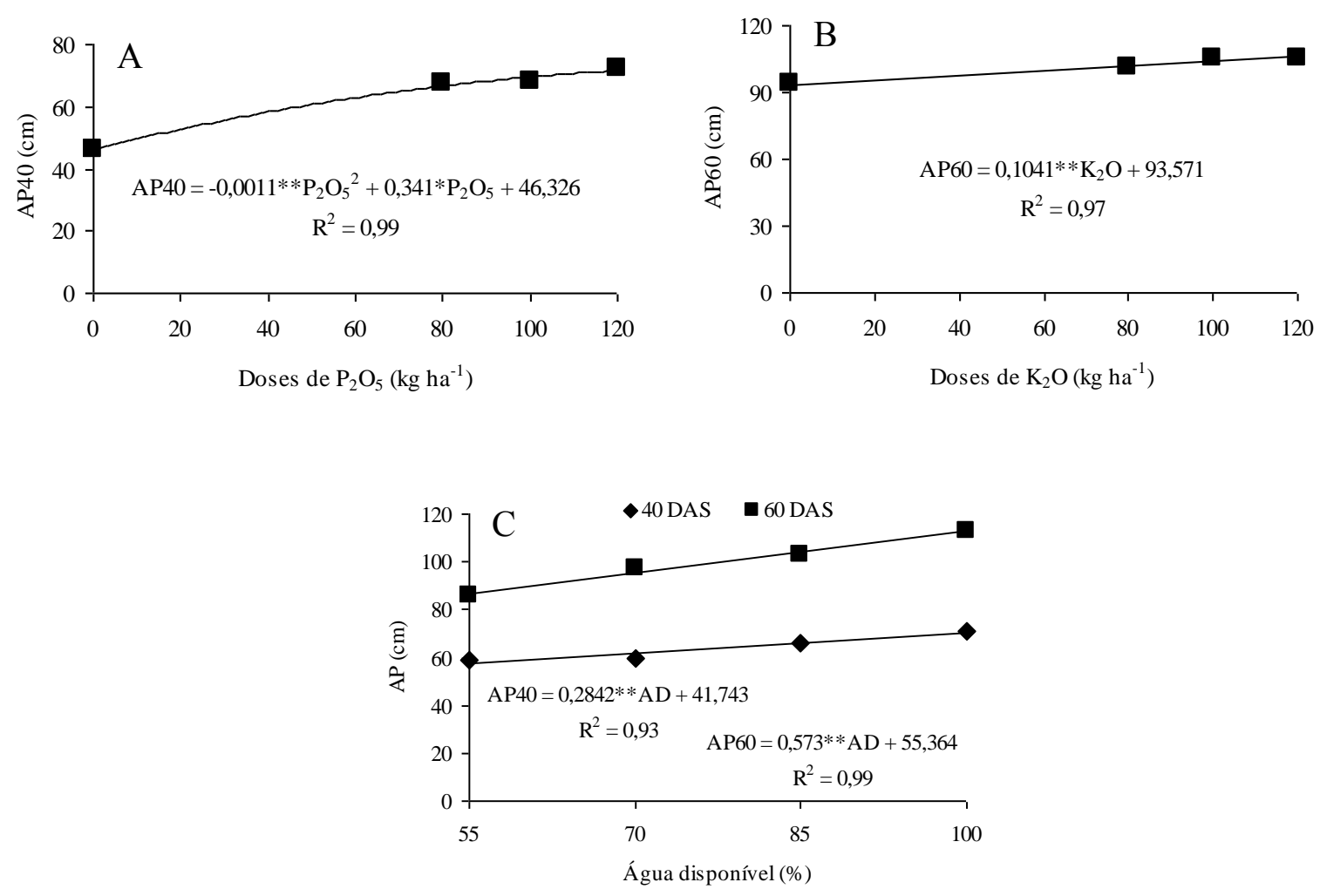

Figura 1. Altura de plantas do girassol Embrapa 122 V2000 aos 40 e 60 DAS em função das doses de $\mathrm{P}_{2} \mathrm{O}_{5}(\mathrm{~A}), \mathrm{K}_{2} \mathrm{O}(\mathrm{B})$ e do conteúdo de água disponível no solo (C).

Tan et al. (2000) relataram que a irrigação plena e limitada aplicada em diferentes fases de crescimento aumentou significativamente o crescimento vegetativo do girassol, particularmente a altura de plantas. Para Gomes et al. (2012), avaliando o desempenho de girassol sob diferentes lâminas de irrigação suplementar, a altura das plantas do girassol cultivar Araguá 4 respondeu de forma linear à irrigação, em todos os estádios analisados.

Muralidharudu et al. (2003) avaliando a resposta do girassol ao fornecimento de $\mathrm{P}$ em Vertissolos, concluíram que a aplicação de fósforo, em geral, resulta no crescimento em altura 
do girassol. Tendências semelhantes foram observadas por Mojiri e Arzani (2003) e Bakht et al. (2010a). Os resultados corroboram também com os obtidos por Soleimanzadeh et al. (2010) ao afirmarem que a altura final das plantas foi influenciada pelas doses de $\mathrm{K}_{2} \mathrm{O}$. Para Mobasser e Tavassoli (2013) os componentes de crescimento e rendimento foram afetados significativamente por diferentes níveis de água de irrigação.

Com exceçao da fertilização NPK aos 60 DAS, o diâmetro caulinar foi afetado estatisticamente pelas doses de fósforo (aos 40 DAS) e nitrogênio (60 DAS). Em relação ao regime hídrico, o diâmetro caulinar, nos períodos avaliados, aumentou significativamente com o incremento da água disponível no solo (Tabela 2).

De acordo com a literatura, o diâmetro do caule é uma característica muito importante no girassol, pois permite que ocorra menos acamamento da cultura e facilita seu manejo, tratos e colheita. Conforme os resultados obtidos, os valores de diâmetro caulinar aos 40 DAS aumentaram com as doses de fósforo, onde essa elevação resultou numa superioridade de $24,86 \%$ da maior dose de $\mathrm{P}_{2} \mathrm{O}_{5}\left(120 \mathrm{~kg} \mathrm{ha}^{-1}\right)$ em comparação ao tratamento controle (Figura 2A). Para os tratamentos fertilizados aos 60 DAS, foi detectado ajuste linear crescente com aumento com as doses de N, proporcionando, assim, uma superioridade de $24,69 \%$ do tratamento $100 \mathrm{~kg} \mathrm{ha}^{-1}$ em relação ao controle (Figura 2B).

Semelhantemente ao observado para a altura de plantas, a água disponível influenciou estatisticamente o diâmetro caulinar de forma linear, resultando em maiores valores da variável $(11,94$ e $13,02 \mathrm{~mm})$ nos tratamentos de $100 \%$ de água disponível, para avaliação aos 40 e 60 DAS, respectivamente (Figura 2C).
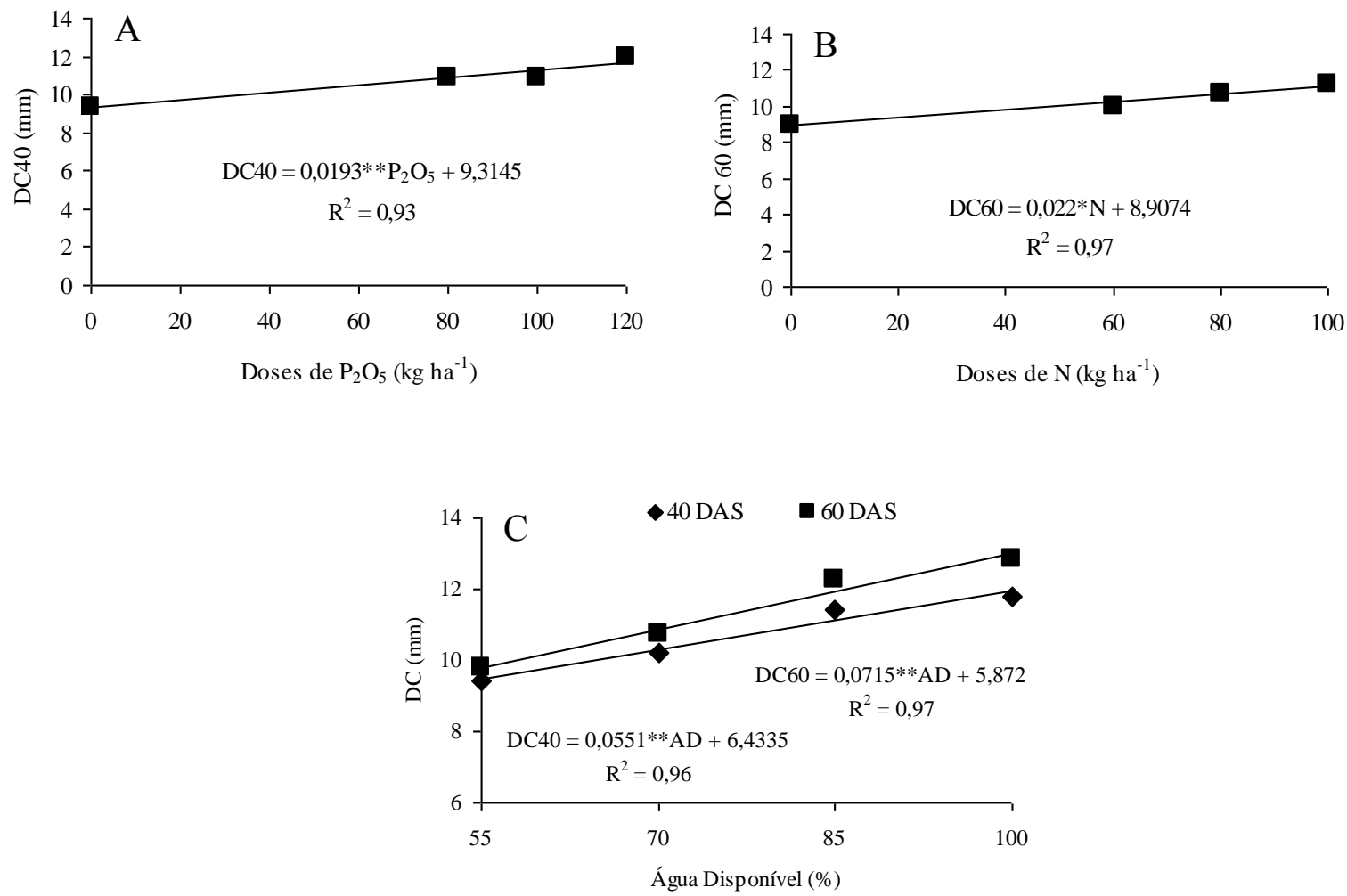

Figura 2. Diâmetro caulinar do girassol Embrapa 122 V2000 aos 28 e 52 DAS em função das doses de $\mathrm{P}_{2} \mathrm{O}_{5}(\mathrm{~A}), \mathrm{N}$ (B) e do conteúdo de água disponível no solo (C).

Avaliando a influência do manejo da irrigação e nitrogênio sobre características agronômicas e rendimento do girassol, Khaliq e Cheema (2005), obtiveram resultados significativos da adubação nitrogenada sobre o diâmetro do caule de girassol. Segundo os 
autores, não foi registrada interação entre irrigação e aplicação de nitrogênio. Esses resultados estão coerentes com os obtidos por Abdel-Motagally e Osman (2010), para adubação com nitrogênio. Sobre o efeito positivo da adubação fosfatada na cultura do girassol, Chaniara et al. (1989) afirmaram que o diâmetro do caule aumentou com o incremento da aplicação de fósforo.

Ayub et al. (1999), ao estudarem o efeito de diferentes fontes e doses de potássio sobre a produçao, as caracteristicas do crescimento e o teor de óleo do girassol, não observaram interferência significativa das doses de potássio no diâmetro do caule.

Os resultados do regime hídrico foram semelhantes aos obtidos por Nemazi et al. (2008), em estudo sobre o efeito do estresse hídrico e desfolha do girassol em condições controladas. Baseado na pesquisa, uma redução no teor de água no solo a 60 e $30 \%$ da capacidade de campo, resultou numa diminuição de 20 e $46 \%$ do diâmetro do caule em relação ao controle, respectivamente. Esses dados também corroboram com os obtidos por Guedes Filho et al. (2013) e Gomes et al. (2012).

O suprimento adequado de fósforo, uma vez que interferi diretamente nas taxas fotossintéticas, resulta no aumento de número de folhas e na área foliar. Por outro lado, a carência deste elemento reduz o número de folhas, porque promove a senescência precoce das folhas mais velhas. Nesta pesquisa o número de folhas do girassol Embrapa 122 V2000 foi influenciado significtivamente pela interação das doses de fósforo vs conteúdo de água disponível no solo aos 40 e 60 DAS (Tabela 3).

Tabela 3. Resumo das análises de variância para o número de folhas (NF) e para área foliar do girassol (variedade Embrapa 122-V2000) aos 40 e 60 dias após a semeadura (DAS) submetida à adubação com NPK e conteúdo de água disponível no solo.

\begin{tabular}{|c|c|c|c|c|c|}
\hline \multirow{3}{*}{ Fonte de variação } & \multirow{3}{*}{ GL } & \multicolumn{4}{|c|}{ Quadrado Médio } \\
\hline & & \multicolumn{2}{|c|}{ Número de folhas (NF) } & \multicolumn{2}{|c|}{ Área foliar $\left(\mathrm{cm}^{2}\right)$} \\
\hline & & 40 DAS & 60 DAS & 40 DAS & 60 DAS \\
\hline Adubação (NPK) & 10 & $17,739^{* *}$ & $39,096^{* *}$ & $185572,53^{* *}$ & $284202,6^{* *}$ \\
\hline Irrigação (I) & 3 & $103,292^{* *}$ & $32,573^{* *}$ & $164600,92^{* *}$ & $215584,0^{* *}$ \\
\hline NPK $x$ I & 30 & $5,004^{\mathrm{ns}}$ & $10,456^{\mathrm{ns}}$ & $152123,03^{\text {ns }}$ & $2071576,7^{\mathrm{ns}}$ \\
\hline Resíduo & 88 & 5,787 & 6,969 & 160614,01 & 22136157 \\
\hline Total & 131 & - & - & - & - \\
\hline CV (\%) & - & 13,78 & 14,47 & 17,10 & 18,70 \\
\hline N - Regressão Linear & 1 & $0,0375^{\mathrm{ns}}$ & $4,150^{\mathrm{ns}}$ & $20681,18^{\mathrm{ns}}$ & $10159,08^{\mathrm{ns}}$ \\
\hline N - Regressão Quadrática & 1 & $2,5208^{\mathrm{ns}}$ & $0,333^{\text {ns }}$ & $1620,37^{\mathrm{ns}}$ & $6138,93^{\text {ns }}$ \\
\hline P - Regressão Linear & 1 & $2,400^{\mathrm{ns}}$ & $9,600^{\text {ns }}$ & $21091,12^{\text {ns }}$ & $11163,99^{\mathrm{ns}}$ \\
\hline P - Regressão Quadrático & 1 & $16,333^{\mathrm{ns}}$ & $40,333^{*}$ & $8478,57^{\mathrm{ns}}$ & $118138,56^{\mathrm{ns}}$ \\
\hline K - Regressão Linear & 1 & $0,337^{\text {ns }}$ & $29,400^{*}$ & $138627,09^{\text {ns }}$ & $252336,47^{\mathrm{ns}}$ \\
\hline K - Regressão Quadrática & 1 & $2,520^{\mathrm{ns}}$ & $10,083^{\mathrm{ns}}$ & $613753,92^{* *}$ & $606012,27^{* *}$ \\
\hline I - Regressão Linear & 1 & $306,818^{* *}$ & $37,346^{*}$ & $137274,10^{\text {ns }}$ & $138340,10^{\mathrm{ns}}$ \\
\hline I - Regressão Quadrática & 1 & $2,454^{\mathrm{ns}}$ & $54,734^{* *}$ & $150103,58^{* *}$ & $861915,63^{* *}$ \\
\hline $\mathrm{N}$ - Linear $\mathrm{x}$ I Linear & 1 & $1,140^{\mathrm{ns}}$ & $4,083^{\mathrm{ns}}$ & $7824,48^{\mathrm{ns}}$ & $56876,65^{\mathrm{ns}}$ \\
\hline P - Linear x I Linear & 1 & $34,003^{*}$ & $36,750^{* *}$ & $15732,64^{\mathrm{ns}}$ & $178750,22^{\text {ns }}$ \\
\hline K - Linear x I Linear & 1 & $17,520^{\mathrm{ns}}$ & $27,603^{* *}$ & $99117,26^{\mathrm{ns}}$ & $263225,01^{\text {ns }}$ \\
\hline
\end{tabular}

Nota: ",** significativo a 5 e $1 \%$, respectivamente, e ${ }^{\text {ns }}$ não significativo, pelo teste F. GL: Grau de liberdade. CV: coeficiente de variação. 
De acordo com a Figura 3A, o número de folhas aos 40 DAS em função da adubação fosfatada aumentou de forma quadrática com os tratamentos de 55; 70 e 100\% AD e de forma linear com $85 \%$ AD sendo que o maior número de folhas (20,81 unidades) foi obtido na dose de $80 \mathrm{~kg} \mathrm{ha}^{-1}$ de $\mathrm{P}_{2} \mathrm{O}_{5}$ sob manejo de irrigação de $100 \% \mathrm{AD}$. Observou-se tambem que na dose de $120 \mathrm{~kg} \mathrm{ha}^{-1}$ de $\mathrm{P}_{2} \mathrm{O}_{5}$, quanto menor o volume de água no substrato, menor o número de folhas do girassol. Isto mostra que o aumento da adubação, entretanto, com deficit hidrico não influencia positivamente o desenvolvimento das plantas.

O número de folhas em função da adubação fosfatada, aos 60 DAS, não foi afetado nos níveis de de 85 e 100\% AD apresentando valores médios de 19,83 e 17,92, respectivamente. No entanto, o número máximo de folhas foi 20,40 unidades correspondente a estimativa de $83,88 \mathrm{~kg} \mathrm{ha}^{-1}$ de $\mathrm{P}_{2} \mathrm{O}_{5}$ com $70 \%$ AD (Figura 3B).

Da mesma forma, o número de folhas das plantas de girassol foi influenciado significtivamente pela interação das doses de potássio vs conteúdo de água disponível no solo aos 60 DAS (Tabela 3). Entretanto, os dados do número de folhas se ajustaram de forma quadrática somente com 55 e $70 \%$ AD cujo maior número de folhas (23,29 unidades) foi obtido na dose estimada de $51 \mathrm{~kg} \mathrm{ha}^{-1}$ de $\mathrm{K}_{2} \mathrm{O}$. Com os tratamentos de 85 e $100 \%$ AD obteve-se valores médios, em torno de 21 e 18 folhas, respectivamente (Figura 3C).
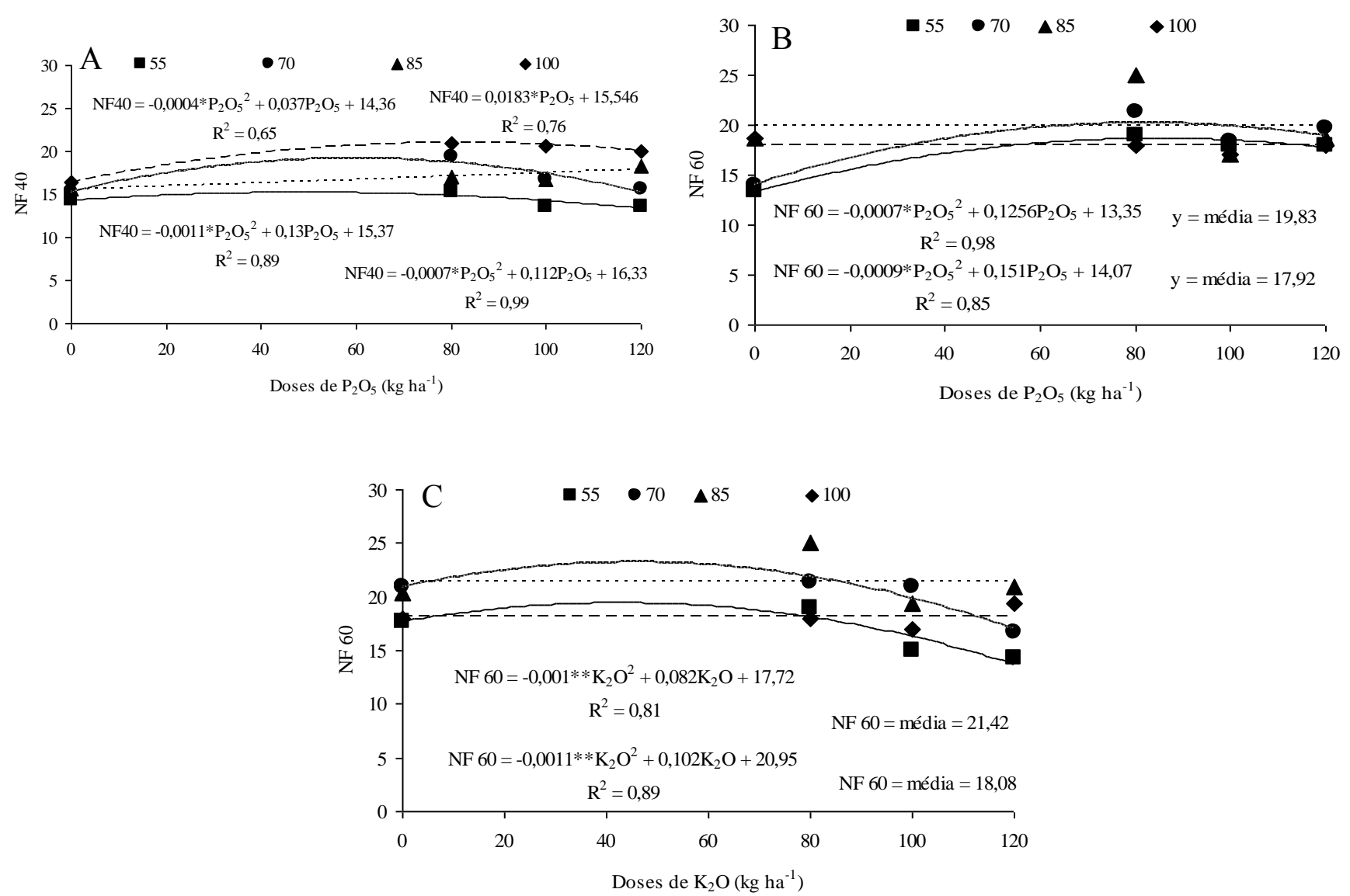

Figura 3. Número de folhas (NF) do girassol variedade Embrapa 122 V2000 em função da interação da adubação fosfatada e conteúdo de água disponível aos 40 (A) e 60 DAS (B) e adubação potássica e conteúdo de água disponível do solo aos 60 DAS (C).

O efeito negativo do estresse hídrico sobre a taxa de aparecimento de folhas de girassol foi registrado por Gholinezhad et al. (2011). Segundo os autores, o máximo e o mínimo de taxa de aparecimento foliar foi obtido com irrigação adequada e estresse hídrico severo, respectivamente. Para Taiz e Zieger (2004), o turgor celular estimula a expansão e ou 
alongamento das celulas; logo a restrição de água limita não só o tamanho, mas também o número de folhas; fatos constatados na presente pesquisa. Os dados do efeito depreciativo do estresse hídrico sobre o número de folhas do girassol, corroboram com os observados por Thakuria et al. (2004) e Bakht et al. (2010b).

De acordo com os resultados da análise de variância apresentada na Tabela 3, os dados da área foliar do girassol Embrapa 122 V2000 foram influenciados significativamente pela aplicação de potássio e conteúdo de água disponível no solo, aos 40 e 60 DAS, ajustados de forma quadrática.

A área foliar, aos 40 e 60 DAS, aumentou de forma quadratica com a aplicação de potássio nas plantas de girassol, obtendo-se os maiores valores com as doses de 70,75 e 72,62 $\mathrm{kg} \mathrm{K}_{2} \mathrm{O} \mathrm{ha}^{-1}$, respectivamente (Figura 4A). Os resultados dessa pesquisa corroboram com os apresentados por Ayub et al. (1999). Pela investigação destes autores, a área foliar máxima do girassol foi obtida na dose de $100 \mathrm{~kg} \mathrm{ha}^{-1}$ de cloreto de potássio.

As plantas com 55\% AD apresentaram uma menor área foliar, nas duas datas avaliadas. Contudo, os maiores valores da área foliar, foram encontrados 83,25 e 77,93\% AD, aos 40 e 60 DAS, respectivamente (Figura 4B). Vários trabalhos encontrados na literatura fazem referência ao efeito negativo do estresse hídrico sobre a área foliar do girassol a exemplo de Tan et al. (2000), Petcu et al. (2001), Thakuria et al. (2004) e Bakht et al. (2010b).
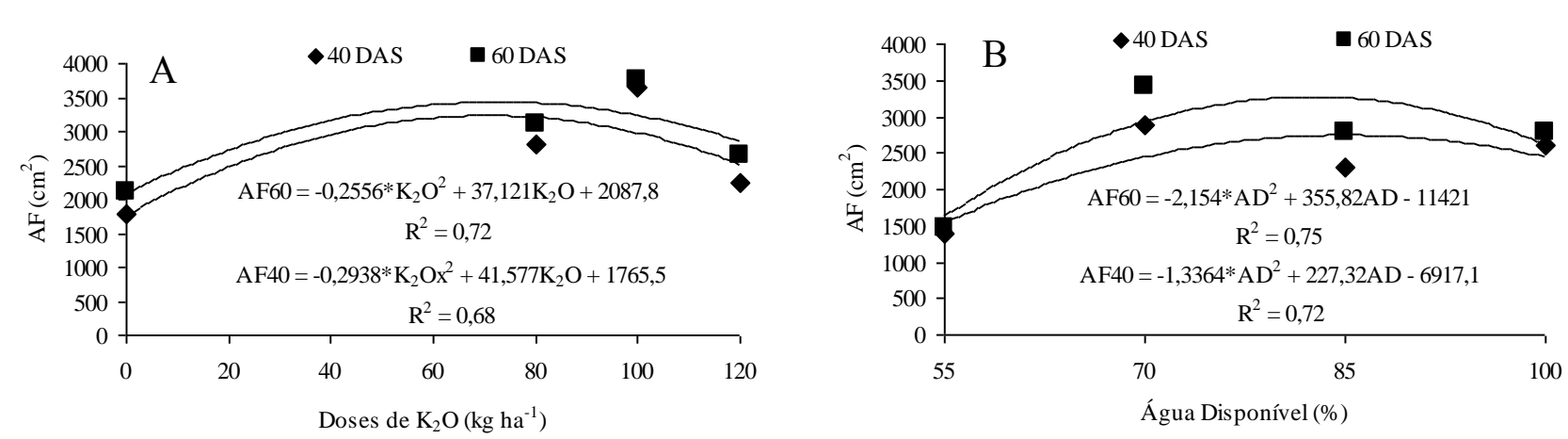

Figura 4. Área foliar (AF) do girassol variedade Embrapa 122 V2000 aos 40 e 60 DAS em função da adubação com $\mathrm{K}_{2} \mathrm{O}(\mathrm{A})$ e do conteúdo de água disponível no solo (B).

Em todas as pesquisas, quer seja sob condições de vaso, quer seja em cultivo de campo, a área foliar do girassol decresceu nos tratamentos com menor conteúdo de água disponível. Esses resultados estão compatíveis com os relatados por Thair et al. (2002), ao afirmarem que plantas de girassol sob estresse hídrico apresentaram redução de $25,56 \%$ da área foliar quando comparado aos tratamentos de $100 \%$ da água disponível. Naim e Ahmed (2010) apontaram que o estresse hídrico diminui a fotossíntese devido ao fechamento dos estômatos. A redução da taxa fotossintética diminuiu a translocação de carboidratos e reguladores de crescimento, o que resulta em redução da pressão de turgescência e da área foliar, além da diminuição do crescimento.

\section{CONCLUSÕES}

A altura da planta, o diâmetro do caule, o número de folhas e a área foliar do algodão foram afetados pela adubação NPK e pelo conteúdo de água disponível no solo para as plantas;

Com exceção da área foliar todas as variáveis apresentaram comportamento linear crescente em função da água disponível do solo; 
Para as condições estudadas, as maiores doses de $\mathrm{N}, \mathrm{P}_{2} \mathrm{O}_{5}$ e $\mathrm{K}_{2} \mathrm{O}$ e o maior conteúdo de água disponível no solo proporcionaram os maiores índices de crescimento.

\section{AGRADECIMENTOS}

Ao Conselho Nacional de Desenvolvimento Científico e Tecnológico (CNPq) pelo financiamento da pesquisa e pela concessão de bolsa de pós-graduação ao primeiro autor.

\section{REFERÊNCIAS}

ABDEL-MOTAGALLY, F. M. F.; OSMAN, E. A. Effect of nitrogen and potassium fertilization combinations on productivity of two sunflower cultivars under East of Elewinate Condictions. American-Eurasian Journal Agricultural and Environmental Sciences, Dubai, v. 8, n. 4, p. 397-401, 2010.

AHMAD, F. Effect of potassium application in different proportions with nitrogen and phosphorus on growth, yield and oil content of sunflower. 1989. 100f. Ph.D - Thesis - University Agricultural, Faisalabad, 1989.

AYUB, M.; TANVEER, A.; AMIN, M. Z.; SHARAR, M. S.; PERVAIZ, A. Effect of differents sources and levels of potash on yield and oil content of spring sunflower. Pakistan Journal of Biological Sciences, Singapore, v. 2, n. 3, p. 801-803, 1999.

BAKHT, J.; SHAFI, M.; YOUSAF, M.; SHAH, H. U. Physiology, phenology and yield of sunflower (autumn) as affected by NPK fertilizer and hybrids. Pakistan Journal Botany Sciences, Singapore, v. 42, n. 3, p. 1909-1922, 2010a.

BAKHT, J. J.; SHAFI, M.; YOUSAF, M.; KHAN, M. A. Effect of irrigation on physiology and yield of sunflower hybrids. Pakistan Journal Botany Sciences, Singapore, v. 42, n. 2, p. 1317-1326, 2010 b.

CASTRO, C; OLIVEIRA, F. A. Nutrição e adubação do girassol. In: LEITE, R. M. V.; BRIGHENTI, B. de C.; CASTRO, A. M. (Ed.). Girassol no Brasil. Londrina: Embrapa Soja, 2005. p. 317-373.

CHANIARA, N. J.; PATEL, J. C.; MALAVIA, D. D.; BALDHA, N. M. Effect of irrigation, nitrogen and phosphorus on the productivity of sunflower. Indian Journal of Agronomy, New Delhi, v. 34, n. 4, p. 399-401, 1989.

EMPRESA BRASILEIRA DE PESQUISA AGROPECUÁRIA - EMBRAPA. Centro Nacional de Pesquisa de Soja. Tecnologia de Produção do Girassol: sistema de produção. Londrina: Embrapa Soja, 2000. 158p.

EMPRESA BRASILEIRA DE PESQUISA AGROPECUÁRIA - EMBRAPA. Centro Nacional de Pesquisa de Solos. Manual de métodos de análise de solo. 2. ed. Rio de Janeiro: Embrapa Solos, 1997. 212 p.

EUCLYDES, R. F. Manual de utilização do programa SAEG (Sistema para análises estatísticas e genéticas). Viçosa: UFV, 1997. 59 p.

FOOD AND AGRICULTURAL ORGANIZATION - FAO. FAOSTAT - Statistics database 2008. Disponível em: <http://apps.fao.org/>. Acesso em: 10 out. 2011. 
GHOLINEZHAD, E.; AYNABAND, A.; GHORTHAPEH, A. H.; NOORNOHAMADI, G.; BERNOUSI, I. Effect of drought and nitrogen rates on grain yield, quality traits and physiological indices in sunflower hybrid Iroflor at different plant density. World Applied Sciences Journal, v. 14, n. 1, p. 131-139, 2011.

GOMES, E. P.; FREDI, G.; ÁvilA, M. R.; BISCARO, G. A.; REZENDE, R. K. S.; JORDAN, R. A. Produtividade de grãos, óleo e massa seca de girassol sob diferentes lâminas de irrigação suplementar. Revista Brasileira de Engenharia Agrícola e Ambiental, Campina Grande, v. 16, n. 3, p. 237-246, 2012. http://dx.doi.org/10.1590/S1415-43662012000300001

GUEDES FILHO, D. H.; SANTOS JÚNIOR, J. A.; CHAVES, L. H. G.; CAMPOS, V. B.; OLIVEIRA, J. T. L. Água disponível no solo e doses de nitrogênio no crescimento do girassol. Revista Brasileira de Agricultura Irrigada, Fortaleza, v. 7, p. 201-212, 2013. http://dx.doi.org/10.7127/RBAI.V7N300016

KHALIQ, A.; CHEEMA, Z. A. Influence of Irrigation and Nitrogen Management on Some Agronomic Traits and Yield of Hybrid Sunflower (Helianthus annuus L.). International Journal of Agriculture \& Biology, Faisalabad, v. 7, n. 6, p. 915-919, 2005 .

MALDANER, I. C.; HELDWEIN, A. B.; LOOSE, L. H.; LUCAS, D. P.; GUSE, F. I.; LUZZI, M. P. B. Modelos de determinação não-destrutivo da área foliar em girassol. Ciência Rural, Santa Maria, v. 39, n. 5, p. 1356-1361, 2009. http://dx.doi.org/10.1590/S0103-84782009000500008

MOJIRI, A.; ARZANI, A. Effects of nitrogen rate and plant density on yield and yield components of sunflower. Journal Science Technics Agricultural Nature Research, New Jersey, v. 7, p. 115-125, 2003.

MOBASSER, H. R.; TAVASSOLI, A. Effect of water stress on quantitative and qualitative characteristics of Yield in sunflower (Helianthus annuus L.). Journal of Novel Applied Sciences, Moorebank, v. 2, n. 9, p. 299-302, 2013.

MURALIDHARUDU, Y.; MURTHY, I. Y. L. N.; REDDY, K. P. C.; REDDY, B. N.; CHANDRANATH, H. T. Response of sunflower (Helianthus annuus L.) to phosphorus application in vertisols. Helia, Novi Sad, v. 26, n. 39, p. 147-154, 2003. http://dx.doi.org/10.2298/HEL1358101S

NAIM, A. M. E.; AHMED, M. F. Effect of Irrigation Intervals and Inter-row Spacing on vegetative growth characteristics in Sunflower (Helianthus annuus L) hybrids in Shambat soil. Journal of Applied Sciences Research, Faisalabad, v. 6, n. 9, p. 1440$1445,2010$.

NEZAMI, A.; KHAZAEIA, H. R.; BOROUMAND REZAZADEHB, Z.; HOSSEINIC, A. Effects of drought stress and defoliation on sunflower (Helianthus annuus) in controlled condition. Desert, Tehran, v. 13, n. 0, p. 99-104, 2008.

PETCU, E.; ARSINTESCU, A.; STANCIU, D. The effect of hydric stress on some characteristics of sunflower plants. Romanian Agricultural Research, Fundulea, v. 16, p. 15-22, 2001.

QUAGGIO, J. A.; UNGARO, M. R. G. Girassol. IN: RAIJ, B. VAN; CANTARELLA, H.; QUAGGiO, J. A.; FURLANI, A. M. C. (Eds.). Recomendações de adubação e calagem para o Estado de São Paulo. Campinas: IAC, 1997. 198p. 
SOLEIMANZADEH, H.; HABIBI, D.; ARDAKANI, M. R.; PAKNEJAD, F.; REJALI, F. Response of sunflower (Helianthus annuus L.) to drought stress under different potassium levels. World Applied Sciences Journal, Dubai, v. 8, n. 4, p. 443-448, 2010 .

TAHIR, M. H. N.; IMRAN, M.; HUSSAIN, M. K. Evaluation of sunflower (Helianthus annuus L.) inbred lines for drought tolerance. International Journal of Agriculture \& Biology, Faisalabad, v. 4, n. 3, p. 398-400, 2002.

TAIZ, L.; ZEIGER, E. Fisiologia vegetal. 3. ed. Porto Alegre: Artmed, 2004. 613 p.

TAN, S.; BEYAZGUL, M.; AVCIERI, Z.; Y. KAYAM, Y.; KAYA, H. G. Effect of irrigation at various growth stages on some economic characters of first crop sunflower. Journal Anadolu, Izmir, v. 10, n. 2, p. 1-34, 2000.

THAKURIA, R. K.; HARBIR, S.; TEJ, S. Effect of irrigation and antitranspirants on growth and yield of spring sunflower (Helianthus annuus L.). Indian Journal of Agronomy, New Delhi, v. 49, p. 121-123, 2004.

ZOBIOLE, L. H. S.; CASTRO, C.; OLIVEIRA, F. A.; OLIVEIRA JÚNIOR, A. Marcha de absorção de macronutrientes na cultura do girassol. Revista Brasileira de Ciência do Solo, Viçosa, v. 34, n. 2, p. 425-433, 2010. http://dx.doi.org/10.1590/S010006832010000200016 